\title{
La frontera tarapaqueña y sus territorialidades desde la crisis salitrera hasta la década dorada (1919-1960)
}

\author{
Luis Andrés Iturra Valenzuela \\ Instituto de Estudios Internacionales, Universidad Arturo Prat, Iquique, Chile. \\ Email: Luis.an.iturravalenzuela@gmail.com
}

Resumen: Posicionándonos en un diálogo teórico entre la perspectiva reflectivista de los estudios en relaciones internacionales y la geografía crítica, se aborda la frontera tarapaqueña en torno a dos objetivos. Primero, problematizar la frontera como un espacio múltiple y de dinámicas simultáneas. Segundo, indagar en la configuración de la frontera tarapaqueña y las territorialidades que los distintos actores políticos y sociales proyectaron durante la crisis estructural del salitre hasta la década dorada de las relaciones diplomáticas chileno-boliviana (1919-1960). Revisando archivos y bibliografía que han abordado la temática del espacio fronterizo, como también a los actores para-diplomáticos durante aquel periodo en Tarapacá. Se identifica el entramado de tres territorialidades distintas en el espacio fronterizo, pertenecientes a actores de diferentes escalas: las Estatales, las regionales, y las de comunidades étnicas. Dichas territorialidades se oponen, yuxtaponen y ensamblan entre sí.

Palabras clave: Territorialidades, frontera, actores diplomáticos, Tarapacá.

\section{The frontier tarapaqueña and its territorialities, $\mathbf{f}$ rom the nitrate crisis to the golden decade (1919-1960)}

\begin{abstract}
Positioning ourselves in a theoretical dialogue between the reflectivist perspective of studies in international relations and the critical geography, the Tarapacá border is approached around two objectives. First, to problematize the border as a multiple space and simultaneous dynamics. Second, to investigate the configuration of the Tarapacá border and the territorialities that the different political and social actors projected from the saltpeter structural crisis until the golden decade of the Chilean-Bolivian diplomatic relations (1919-1960). Reviewing archives and bibliography that have addressed the issue of border space, as well as paradiplomatic actors during that period in Tarapacá. The framework of three different territorialities in the border space belonging to actors of different State/ regional/ethnic communities' scales are identified. They are opposed, juxtaposed and assembled one to another.
\end{abstract}

Keywords: Territorialities, border, diplomatic actors, Tarapacá. 


\section{A fronteira de Tarapaque e as suas territorialidades desde a crise dos nitratos até à década de ouro (1919-1960)}

Resumo: Posicionando-nos num diálogo teórico entre a perspectiva refletivista dos estudosemrelaçõesinternacionais e geografia crítica, a fronteiraTarapaque é abordada em torno de dois objetivos. Primeiro, problematizar a fronteira como espaço múltiplo e dinâmicasimultânea. Em segundo lugar, investigar a configuração da fronteira territorialidades Tarapaca e os diversos atores políticos e sociaisprojetadas durante a criseestrutural do salitre à década de ouro das relações diplomáticas do Chile-Bolívia (1919-1960). Revendo arquivos e bibliografia que abordaram a questão do espaçofronteiriço, bem como atores para-diplomáticos durante esse período em Tarapacá. O quadro de três diferentes territorialidades na área de fronteiraé identificado, pertencendo a atores de diferentes escalas: Estado, comunidades regionais e étnicas. Essas territorialidades sãoopostas, justapostas e unidas.

Palavras-chave: Territorialidades, fronteira, atores diplomáticos, Tarapacá.

$$
* * *
$$

\section{Introducción}

Esta contribución pretende estudiar la frontera tarapaqueña entendida como un espacio fronterizo en la cual se encuentran múltiples territorialidades proyectadas por una pluralidad de actores, donde las ideas de frontera abierta y cerrada como también de separación y encuentro son parte de aquel espacio. Territorialidades que corresponden a representaciones de producción cultural, social e histórica en el ámbito del poder y la configuración del espacio, que durante la crisis estructural del salitre posibilitó un distanciamiento y división entre diversas autoridades respecto a la proyección espacial de Tarapacá en el desarrollo y devenir de la región.

Después del auge del salitre, y acontecido el periodo de crisis estructural del nitrato, el interés estratégico del Estado de Chile en la pampa y la costa producto de la industria y renta del salitre culmina y pasa a trasladarse a la problemática de la precaria presencia de institucionalidad estatal en el espacio fronterizo andino (Castro, 2008). Años antes, durante el ciclo de expansión del nitrato, la urbanización de la ciudad de Iquique fue central en el proceso de chilenizar el territorio tarapaqueño, convirtiéndose en el principal punto de referencia "urbana de la zona de frontera en el norte del país” (González, 2009a, p. 24), mientras la pampa basaba su importancia en la industria salitrera.

Fueron las dinámicas durante el ciclo del salitre las que dispusieron abrir las fronteras. Las salitreras se abastecieron del tráfico comercial y migraciones transfronterizas, que permanecieron desde la anexión de la provincia de Tarapacá a Chile y en todo el ciclo de expansión (González, 2009b, p. 76). Como señalan Ovando y Ramos (2016) “el espacio fronterizo tarapaqueño se ve imbuido en realidades múltiples con sus propias valora- 
ciones sobre el espacio" (p. 6), un espacio que no es ajeno a la temporalidad y que se constata en la espacialidad (Núñez, 2013).

El presente trabajo se articula en base a dos objetivos, uno teórico y otro histórico. El primer objetivo pretende problematizar la frontera como un espacio múltiple, diverso e irreductible a lo estatal, puesto que ésta es sólo una de muchas formas de concebirla y, como señalan Núñez, Sánchez y Arenas (2013), Amilhat-Szary (2013) y Balibar (2005; 2009), es una espacialidad donde acontecen dinámicas simultáneas.

El segundo objetivo consiste en indagar en la configuración de la frontera tarapaqueña y las territorialidades que los distintos actores políticos y sociales proyectaron durante la crisis estructural del salitre hasta la década de los 50.

Nos posicionamos en una perspectiva reflectivista de los estudios en relaciones internacionales, dialogando con la geografía crítica. Por reflectivista nos referimos a una corriente de pensamiento que se opone al Mainstreamy que pone en el centro del análisis al Estado, sus instituciones y agentes, reduciendo e incluso ignorando la participación de otros actores en el ámbito de la política exterior.

Dentro de esta corriente de pensamiento se encuentran los estudios críticos y posestructuralistas; aquellos han retomado concepciones clásicas de la corriente dominante, pero cuestionando sus categorías de análisis, observando la participación de diversos actores sociales en temas donde el mainstream los ignoraba (Sodupe, 2003; Ashley, 2009).

Es en este devenir donde la frontera ha comenzado a ser de interés (Agnew, 2006), pues no se reduce al límite, sino que a un espacio social y donde la diplomacia es comprendida como "las más diversas expresiones de la vida social” (Cornago, 2016, p. 11). Un espacio donde se reconfiguran estas relaciones de alteridad (Constantinou, 2010). Distanciándonos de la visión tradicional de diplomacia como una exclusividad de los Estados.

Debemos considerar que la frontera se ha constituido como una de las bases para la nueva interpretación de las relaciones internacionales y más aún para la diplomacia (Constantinou, 2010), porque es en ella en donde puede observarse a los actores sociales que ponen en jaque las concepciones tradicionales de aquella disciplina. En aquel espacio se manifiesta la diplomacia en su sentido original, que consiste en la voluntad de grupos humanos de relacionarse con tal de escapar de la guerra y la desconfianza, superando la alteridad como barrera y en donde el pluralismo era el impulso primordial de una diplomacia heterológica (Cornago, 2016, p. 17). Distante de una visión estadocéntrica; siendo parte de un abanico mayor de actores (Cornago, 2015).

La serie de actores subnacionales pueden rastrearse en, “el intento de historizar el concepto de frontera para entender mejor el posicionamien- 
to de los actores que la conforman” (Amilath-Szary, 2016, p. 49), llámese paradiplomacia (Constantinou, 2010), pluralismo diplomático (Ovando y González, 2016) o diplomacia como heterología (Cornago, 2016). Son nuevas nociones que integran un conjunto de múltiples actores que en ocasiones suelen estar en contraposición a lo que dictan los Estados desde su nivel central.

Esto conlleva a hacer uso de la geografía crítica que plantea una nueva geopolítica influenciada por la teoría crítica y el posestructuralismo. Orientados a la vinculación entre espacio y poder, reorientando una mirada hacia los actores y la flexibilidad de las escalas espacio-temporales, donde no interesa sólo el territorio del Estado nación, "sino también las territorialidades móviles, temporales y de límites elásticos” (Benedetti y Salizzi, 2011, p. 150). El concepto de Territorialidad(es) es relevante, comprendido como la definición del espacio que hacen los sujetos sociales, donde el territorio es un resultado que se define en formas superpuestas, conflictivas y asociadas (Haesbaert, 2013; Benedetti, 2014).

$\mathrm{Al}$ posicionarnos en el reflectivismo, desde la genealogía, el dato histórico se hace fundamental como método de estudio (Der Derían, 1998; Esteves, 2006) donde:

No se buscaría determinar los orígenes de las ideas, instituciones o prácticas, sino, identificar las procedencias y emergencias de las prácticas cuyo ritmo y dirección se determinarían en el eterno combate entre verdades que demarcan los vencedores y los derrotados. (Rodríguez, 2013, p. 95).

Interesa, por ende, indagar en esos diversos discursos y prácticas que los actores desarrollaron entorno al espacio fronterizo durante la crisis estructural del salitre hasta finales de la denominada década dorada de las relaciones chileno-boliviana. Revisando el Archivo Regional de la Intendencia de Tarapacá (ITAR) como fuente primaria, junto a la bibliografía que ha abordado la temática del espacio fronterizo, así como también a los actores (para)diplomáticos durante aquel periodo en Tarapacá. Periodo en que la respuesta de autoridades regionales a la adversidad de la crisis sería mediante estrategias de desarrollo con proyección transfronteriza: los comités pro-ferrocarril y pro-camino.

Simultáneamente se encuentra una concepción territorial aún más compleja y dinámica asociada a comunidades-localidades más próximas al límite de los Estados; los habitantes de (trans)frontera quienes se disputaban los territorios agro pastoriles.

Las próximas páginas se encuentran divididas en los siguientes apartados: Primero se discutirá la espacialidad fronteriza y sus territorialidades. En segundo lugar, se indaga en el periodo de crisis estructural del salitre y en específico en la disposición del Estado respecto al espacio fronterizo, para luego adentrarnos al apartado de los procesos transfronterizos y el 
hito de las caravanas de la amistad. Por último, la territorialidad desplegada por los habitantes indígenas de frontera. Cerrando con las conclusiones sobre los tres actores que proyectaron sus propias territorialidades hacia el espacio fronterizo; oponiéndose, yuxtaponiéndose y en ocasiones acoplándose entre ellas.

\section{Espacialidad fronteriza y territorialidades}

La frontera ha dejado de reducirse a lo geográfico y, si bien es una variable a considerar, lo que importa aún más son los procesos de fronterización en donde confluyen dinámicas sociales, económicas y culturales. Los estudios más recientes han permitido distinguir entre frontera, como límite de los Estados o como espacios fronterizos; siendo el último concepto un espacio contiguo a la frontera y donde las prácticas cotidianas de quienes habitan son afectadas, la construyen, modifican e incluso la portan en sus cuerpos (Newman, 2006; Amilhat-Szary, 2013, 2016; Balibar, 2005).

Captando las materialidades, las fracciones y representaciones tanto prácticas como discursivas, se reconoce la variabilidad de la frontera sin reducirla a la escala nacional (Brambilla 2015), haciendo de la frontera un medio más ubicuo y de múltiple de contactos (Balibar, 2009). Lo mismo con el territorio, que se había limitado a lo observable, lo físico y a la concepción de la soberanía estatal, superponiéndose a las realidades sociales circunscritas en esos espacios (Benedetti, 2011).

La espacialidad fronteriza no reduce la frontera en un delimitador del territorio nacional. Al no reducir la frontera al concepto de límite, el espacio fronterizo integra a la línea, la zona fronteriza y la región fronteriza. La línea no se reduce a la demarcación política administrativa de la nación, como sí lo hace el límite, sino que se trata de imaginarios donde se da el encuentro con lo otro (Medina, 2006, González, 2009a). Por su parte, la zona fronteriza es el espacio en el cual se desarrollan una serie de actividades dinamizadas en torno a la frontera dentro de un Estado, y la región fronteriza constituye la convergencia de dos o más Estados (Tapia y Ovando, 2013, p. 247). Sin embargo, estas distintas espacialidades no dejan de estar definidas por los imaginarios geográficos, referido a los significados que se proyectan sobre el espacio fronterizo (Baily,1989), y de territorialidades (Benedetti, 2011; Spíndola, 2016).

Como menciona Haesbaert (2013) "cuando se mira el espacio centrando el enfoque en las relaciones de poder, se está viendo y se está identificando un territorio (...) el territorio sería una dimensión del espacio cuando el enfoque se concentra en las relaciones de poder”.(p. 20):

El concepto de territorio es tomado como categoría heurística, como forma de apropiación del espacio por parte de los sujetos sociales, la cual no está ajena a las relaciones de poder, disputas y resistencias de quienes 
definan el espacio a partir de prácticas materiales y simbólicas. Aquel concepto está dotado de una "premisa multiescalar sobre la organización social del espacio” (Benedetti, 2014, p. 15) que está en constante construcción y donde la territorialidad es un constructo cultural (Spíndola, 2016).

Lo que acontece son constantes territorializaciones donde se presenta lo móvil y lo inmóvil o lo que en el caso de la frontera puede ser el cruce y la separación, presentándose de forma simultánea. Aquello, Haesbaert lo denomina multiterritorialidad: "la posibilidad de tener la experiencia simultánea y/o sucesiva de diferentes territorios reconstruyendo constantemente el propio” (2013, p. 34-35). Tal sentido se forja bajo formas de poder sobre el espacio que Foucault abordó: “el territorio del poder soberano, la disciplina para la sociedad disciplinaria y el medio para las sociedades de control” (Haestbaert, 2013, p. 29); éste último será el que posteriormente Foucault denominará gubernamentalidad (2006, p. 140). Formas de poder reticular de discursos y materialidades que construyen realidad y moldean subjetividades (Agamben, 2011; Foucault, 1979); misma red en que emerge la frontera en clave de control vista como un medio de circulación de los flujos de mercancía, bienes y personas (Foucault, 2006).

Es así que, la frontera o más bien la espacialidad fronteriza, no se agota en esta noción del poder soberano, ni en la trampa territorial del Estado como contenedor geográfico de la sociedad y la cultura (Agnew, 2005), sino que constituye diversas dinámicas territoriales simultáneas.

El espacio territorial -más que el límite- da cuenta de la heterogeneidad de los diversos actores sociales que son parte de relaciones entre ambos lados de las fronteras estatales (Oddone, 2016).

\section{La frontera tarapaqueña durante la crisis estructural del salitre: territorialidades y disposiciones del Estado}

Tradicionalmente la historiografía consideró que el fin del ciclo del salitre fue en 1930 ,

Ocultando así el papel desempeñado por una diversidad de factores internos en su propia explicación, como fue el predominio generalizado de la imprevisión, la obsolescencia tecnológica, la rigidez del sistema tributario nacional, la especulación comercial, la colusión de las empresas a través de las combinaciones salitreras, entre otros múltiples aspectos. (González, Calderón y Artaza, 2016, p. 106).

Es durante la administración del Estado-Nación peruano que inicia el ciclo de expansión del salitre y duraría hasta 1919. Sin embargo, durante el año 1914 se expresarían los primeros síntomas de la crisis salitrera. El inicio de la Gran Guerra generó problemas en las exportaciones y la industria. El gobierno de entonces presentó al Congreso un plan de obras públicas 
enfocado en la construcción de líneas férreas en Iquique y Antofagasta; atendiendo a los obreros que quedaban desempleados, proporcionando transporte hacia la zona central del país y disponiendo de cocinas populares. Pero, aún más importante será promover la continuidad de las oficinas salitreras que estaban a punto de cerrar con la Ley de Auxilios Salitreros en agosto de 1914. Para el año siguiente el precio del salitre subiría y las oficinas que se habían cerrado reabrirían gracias a la demanda para la fabricación de explosivos, cuestión que se sostendría hasta finalizar la guerra mundial (Couyoumdjian, 1974).

Si bien la crisis estructural del salitre se dio por la pérdida del mercado alemán como resultados de la Gran Guerra y la consolidación del nitrato artificial en el mercado mundial de fertilizantes (González, 2014), el impacto fue aún más fuertedebido a los factores internos y al desarrollo monoexportador del país (González, et al, 2016). Puesto que, tras la Guerra del Pacífico y ocupación de Tarapacá los ingresos entorno al nitrato de soda se volvieron en el pilar de la economía chilena, representando, "el 46,4\% de las entradas nacionales entre 1899 y 1910” (Donoso, 2011, p. 2).

Pese a la bonanza salitrera en el país, las condiciones en oficinas y centros urbanos de la provincia fueron marginales. El descontento social que se produjo debido a esta situación, "se expresaría en paralizaciones obreras y en manifestaciones xenófobas, vinculadas tanto a la inestable condición de la frontera norte como a la desesperanza colectiva derivada de la crisis” (Donoso, 2011, p. 3). Y es que desde la integración del territorio tarapaqueño no se generó ninguna propuesta del Estado en materia de fomento, con la salvedad de la creación del Ministerio de Industria y Obras Públicas en 1988, sino que funcionó acorde a los intereses de la iniciativa privada.

La anexión tardía y la distancia territorial con el centro de poder propiciaron que, para el Estado, Tarapacá se convirtiera en un territorio enfocado al extractivismo (Ovando y Ramos, 2016).

La respuesta a la adversidad de la crisis y del abandono sería con un emergente sentido de desarrollo con proyección transfronteriza: mediante los comités pro-camino y pro-ferrocarril. Un discurso que se fue gestando desde las élites regionales, pero que en el contexto de crisis tomaría un posicionamiento político regional.

Ante aquel contexto la apuesta era, "construir una moderna conexión física entre dos regiones complementarias, dejando atrás los viejos caminos troperos que, sin embargo, seguían siendo utilizados para el transporte de personas y mercaderías” (González, 2011, p. 66).

\section{Como señala Sergio González (2016)}

Hay autores que lo han denominado como un capital, a lo Bourdieu, un capital integracionista paradiplomático que se fue tejiendo entre 
las regiones contiguas de Tarapacá y Oruro. Que al mismo tiempo es una deconstrucción del otro y de la idea de frontera propias del realismo. (p. 205)

Este capital diplomático es el que denominamos como heterológico, es decir, aquel impulso original por "gestionar la diferencia entre grupos humanos mediante un conjunto de prácticas, instituciones y discursos" (Cornago, 2009, p. 3).

De lo anterior, un ejemplo es la carta de 1902 de la comunidad de vecinos de Iquique hacia el Gobierno del presidente Germán Riesco, marcando un hito de lo que en adelante será un discurso político regional, advirtiendo de una posible hecatombe en la región cuando aún se vivía en el esplendor del ciclo del salitre y cuya apuesta era vincular con un ferrocarril Tarapacá con el territorio boliviano, aquella señalaba:

A nombre de los veinte mil hombres que trabajan en la pampa y de los ochenta mil que pueblan el resto de la provincia, condenados, no solo a quedar sin trabajo sino también a perder el fruto de laboriosas economías invertidas en propiedades que perderán todo su valor; a nombre de los bien entendidos intereses industriales, comerciales y políticos que puedan desarrollarse entre Chile y Bolivia mediante este ferrocarril; a nombre del engrandecimiento inmediato que traerían a la provincia las nuevas industrias y fuentes de trabajo que se implantarían con el establecimiento del nuevo ferrocarril; y por último, en nombre de la paz que se vería afianzada sobre las bases del mutuo conocimiento y del interés recíproco comercial, venimos os vecinos de Iquique en rogar encarecida y respetuosamente a la primera autoridad de la República que se digne en tomar en cuenta, en los momentos oportunos.(Sánchez, 2006, p. 24)

La iniciativa ferroviaria respondía a una futura crisis del salitre y también a una necesaria integración entre países; en donde la relación diplomática entre ambos había estado marcada por la resolución de litigios. El Tratado de Paz y Amistad de 1904 será la diana que acentuó una afinidad entre los Estados-nacionales poniendo en relevancia los intereses empresariales de la minería boliviana y el de las regiones del Norte Grande de Chile (Ovando y González, 2014, p. 37). Esta coincidencia de intereses se conservará hasta que en 1920 Bolivia cambie de parecer, demandando por primera vez a Chile ante la Liga de las Naciones para revisar el Tratado de 1904 contemplando una salida al mar. Sin embargo, la solicitud sería rechazada por encontrarse fuera de plazo. Bolivia esperaba que se le cediera el territorio de Arica; pero con la redacción del artículo $1^{\circ}$ del Protocolo Complementario del Tratado de Lima en 1929 las puertas se cerraban, pues aquel menciona que los territorios de Arica y Tacna no se podían "ceder a una tercera potencia” (González, 2008).

Aquello articuló una contención territorial de la soberanía del Estado, el límite, trazando las relaciones de poder referidas al espacio fronterizo 
(Esteves, 2003) y tejiendo las estrategias de control sobre territorialidades opuestas a la estatal (Ashley, 2009; Spíndola, 2016). Se trata de disposiciones que se contraponen al proyecto transfronterizo de los actores subnacionales y de las prácticas socioespaciales allende la frontera (Ovando, 2015, p. 131).

Ante la deteriorada relación de ambos países, producto de litigios y demandas, sumado al contexto de crisis, el interés del Estado por la frontera comienza a dar un giro. Un oficio dirigido al Ministro del Interior el 21 de Junio de 1929 por el entonces Intendente de Tarapacá, Nemmesio Valenzuela, mencionaba:

Tengo el honor de elevar a US. oficio por el que se da cuenta de una violación de la frontera del territorio nacional, llevada a cabo por tropa armada o policía boliviana, en el paso de Cordillera entre "Ysluga” y el lugar denominado "Pampa de Prajalla”, más o menos a $68^{\circ} 50^{`}$ latitud, ocurrida en los últimos días de Mayo último.- Lo que remito a US. Para su conocimiento y superior resolución.- (Oficio de los Ministerios, 1929, ITAR-1492, foja 340).

Cuestión que continuaría siendo investigada en los meses venideros y se proseguirá a una carta dirigida Legaciones de la Paz:

Acompaño a US. los antecedentes de un denuncio hecho ante las autoridades de Tarapacá, y que la Intendencia de esta provincia ha elevado al Ministerio de mi cargo, sobre violaciones de nuestra frontera por tropa armada de policía de Bolivia, seguidas de atropellos y despojos a ciudadanos chilenos.- Sírvase US. Llevar estos hechos en forma amistosa, a conocimiento de ese Gobierno, para la correspondiente investigación y a fin de que en lo sucesivo se eviten estos incidentes que perturban las buenas relaciones de ambos países.Después de una prolija indagatoria, US., hará presente que si la autoridad Boliviana confirma los hechos reclamados, procedería la devolución de las especies y valores indebidamente expropiados (Oficios generales, 1929, ITAR-1482, foja 27)

Anteriormente el espacio andino era constantemente cruzado por obreros, comerciantes e indígenas. De hecho, con estos últimos se dieron muchas disputas entre particulares y comunidades de un lado y del otro de las fronteras estatales. Conflictos que solían quedar en las disputas por las tierras productivas; pero también era espacios de integración entre la misma cultura. El Estado ignoraba aquellos conflictos próximos a la frontera. Aquello acontecía en periodos de bonanza salitrera donde la frontera era abierta y donde la administración del Estado de Chile era prácticamente nula en el espacio andino.

Tras la crisis del salitre se desplazaría una preocupación hacia la frontera, configurando el discurso y materialización de la territorialidad estatal: de lo que pertenece y no a la soberanía territorial (Nasi, 1998): “una 
imagen del más-allá-del-estado como un espacio de caos y violencia el argumento fundamental para legitimar el Estado como institución necesaria para salvar y proteger a cada uno" (Rodrigues, 2014, p. 99). Gestándose una vigilancia sobre la frontera, y luego un disciplinamiento de la población indígena en los espacios de precordillera y el altoandino, mediante la chilenización escolar.

Así, el interés sobre el espacio fronterizo se empecinó en aquellos que violaban la territorialidad del Estado-Nación:

Por informaciones particulares, y por alusión contenida en el editorial de "El Tarapacá" de esta fecha, me he impuesto de que últimamente han ingresado al país por la cordillera, algunos ciudadanos bolivianos en forma clandestina. Ruego a Ud., se lo tiene a bien, se sirva recomendar vigilancia estricta a las autoridades de la frontera, a fin de impedir el ingreso de bolivianos que no tengan sus pasaportes en debida forma (Martilleros, registros civiles, Cónsules, 1932, ITAR-580, foja 219).

\section{Otro oficio de 1937 menciona:}

Acuso recibo de la providencia Núm. 1064, de $1^{\circ}$ de Febrero ppdo., de SS., del Ministerio de Relaciones Exteriores, sobre amparo que piden los indígenas bolivianos, sobre supuestas violaciones de parte de autoridades chilenas del límite con Bolivia.-

El informe de Carabineros Núm. 1662, de 16 de Marzo ppdo., que en original se acompaña, establece claramente: "Que el personal de Carabineros persigue a los indígenas que se dedican al pastoreo y cuyas tierras están comprendidas en el lado chileno. Sólo se ha limitado a tomas las medidas legales que corresponden entrar al territorio nacional contraviniendo las disposiciones vigentes sobre el particular.” (Oficios de los Ministerios, 1937, ITAR-1687, foja SN).

La necesidad de abordar tales problemáticas se debe tanto al conflicto diplomático como a la gran depresión que daba paso al fin del esfuerzo por mantener una industria moribunda. Así, el cruzar la frontera se transformaba en problema.

De hecho, la misma hoja de coca por la trayectoria que debía recorrer para ingresar a la región mediante llamero, arrieros y por ferrocarril constituía en sí un bien de consumo transfronterizo cuyo valor principal era el de los pueblos andinos, principalmente aymara y que mediante la migración pendular de población boliviana el consumo se instaló en la sociedad pampina (González, 2016). Por lo cual era un flujo que circunscribía una espacialidad como región fronteriza.

Por ende, el consumo de la hoja transfronteriza pasó a ser tema problemático para la lógica del Estado. Si bien durante el auge del ciclo del 
salitre el consumo de coca fue de importancia para el rendimiento de la mano de obra boliviana, acontecida la gran crisis mundial esta hoja transfronteriza comienza a ser restringida. Se comienza a inhabilitar los permisos otorgados años antes, mientras que en otros casos se les restringe la internación de la sustancia.

Aunque el cuerpo de Carabineros mantiene una vigilancia constante para reprimir el contrabando de la coca, sin embargo no ha podido impedir que la internación clandestina de dicha droga siga efectuándose, debido a que en la provincia existen numerosos pasos de comunicación con Bolivia a donde la vigilancia no puede Hacerse efectiva (Memorias, Dirección de Salud, 1929. ITAR-1484).

Sin embargo, el aparato estatal en la zona fronteriza continuaba siendo escaso, será más bien otra la disposición de la razón de Estado la que se plasmará en el territorio del altoandino. Por un lado, el disciplinamiento de las comunidades mediante la chilenización escolar y, por otro lado, el Estado en su relación diplomática con el vecino país que tendrá en los años 50 la mejor época en las relaciones vecinales boliviana-chilena, pero que a pesar de aquello será infructuosa para las intenciones de proyección transfronteriza.

\section{Los procesos transfronterizos y el hito de las caravanas de la amistad de 1958}

La valoración de las escalas subnacionales al igual que el surgimiento de nuevos conflictos producto del entrecruzamiento y superposición de actores, espacios y competencias no son nuevos, sino de larga data presentes en el Norte Grande de Chile (Oddone, 2016; Cornago, 2009).

Pese a que los proyectos ferroviarios fueron la base de las mediaciones entre los Estados de Bolivia y Chile éstos no favorecieron a Tarapacá, siendo desplazada por las conexiones ferroviarias de Arica la Paz y la de Antofagasta con Oruro, haciendo infructuosos los intentos de la élite local.

Acciones de democratización de la política exterior desde niveles subnacionales (Oddone, 2016) realizadas por tarapaqueños se expresan en las palabras del General de Ejército en retiro Carlos Hans Espejo un 11 de julio de 1928 bajo la idea de complementación económica entre Oruro e Iquique, resolviendo a su vez el problema entre ambos países (Ovando y González, 2014, p. 43).

La ventajosa circunstancia de tener a cargo de la Suprema magistratura de la nación no un simple Gobernante, sino un superhombre que, con singular clarividencia se ha preocupado especialmente del futuro comercial y económico de la provincia de Tarapacá, ha sido un poderoso estimulo que nos ha impulsado a elevar hasta su alta 
consideración los diversos proyectos recomendables, unos más que otros, sobre la construcción del Ferrocarril Iquique-Oruro. Y por esa misma circunstancia opinamos que se ofrece la ocasión propicia para que se entable una encuesta por la prensa en que personalidades interiorizadas de la materia, opinen sobre los trazados y determinen el que debe prevalecer y dar margen al proyecto definitivo, que una Comisión, oficialmente designada, presentaría al Supremo Gobierno (...) Lejos está de ser producto de mera fantasía lo que decimos de esta provincia. Hay razones de peso, basadas en imperiosas necesidades que exigen la realización de algunos de los trazados en estudio entre los puntos más arriba indicados. Esto so pena de acarrear fatalmente, por su no ejecución, azarosos años de despecho, ante prejuicios incalculables funestísimos en tiempo de guerra no solo regionales sino generales, y aún haciendo codiciar el florecimiento de la República Argentina, que afana en seguir atrayendo la corriente comercial más importante de Bolivia.

En el presente folleto probaremos lo expuesto y, basando las materias, sobre todo las referentes a las riquezas minerales y agrícolas existentes entre Oruro e Iquique, en conocimiento y apreciaciones autorizadas, habremos puesto nuestro estudio y criterio al servicio de los intereses generales del país y del Supremo Gobierno, quien ha de encomendar a los técnicos el proyecto definitivo sobre la vía férrea que haya de proporcionar a Bolivia salida hacia el Océano Pacífico... (El Tarapacá, 11 de junio de 1928, citado en Ovando y González, 2014, p. 42-43)

El contexto económico y político determinarían las proyecciones territoriales transfronterizas entre Iquique y Oruro en el siglo xx. Proyección que habían tenido precedentes durante la administración peruanaen el año 1864donde las élites locales plantearon la necesidad de una conexión en la cual se articularan los dos polos mineros de Oruro con el estaño y Tarapacá con el nitrato. Como señala Jessop (2004, p. 38) las estrategias económicas descentralizadas de las regiones junto a otras afinidades se vuelven claves en la configuración de regiones transfronterizas. Un deseo de complementariedad económica de la élite regional que discursivamente se integraría al imaginario local (González, 2011; 2012).

Si bien el Tratado de Lima había marcado un distanciamiento, será en los años 1950 donde se vivirá lo que algunos autores denominan la época dorada de las relaciones diplomáticas entre Bolivia y Chile (Ovando y González, 2016).

Aquello permitió que se profundizara el discurso local de vincular la región de Tarapacá con el vecino país. Un titular del periódico regional del año 1950 señala las pretensiones integracionistas del presidente del Rotary Club de Humberstone, Armando Ramírez, y los beneficios de este a la región:

El señor Ramírez, en su charla, hizo un análisis sobre las proyecciones que tendría para la región norte de Chile el aprovechamiento de 
las aguas de los lagos del altiplano. Aportó valiosos datos estadísticos sobre la actual producción agropecuaria de los departamentos de Arica e Iquique, superficie cultivada y cultivable de contarse, en este último aspecto, con el agua suficiente para el regadío. Se refirió extensamente al importante proyecto delineado por el Ingeniero señor Lagarrigue en 1929 e hizo alusión a las gestiones realizadas por el Embajador boliviano, señor Alberto Ostria Gutiérrez. Para completar aún más su charla, el señor Ramírez exhibió tres gráficos. Finalizó diciendo: "Al terminar mi modesta interpretación sobre los beneficios que reportaría a la zona norte el aprovechamiento de los lagos bolivianos, tanto en el aspecto económico, como político e internacional, sólo me resta esperar, compañeros rotarios de los tres países hermanos, en especial, y de toda América en general, que aunemos nuestras voluntades y nuestros pensamientos para cooperar al magnífico esfuerzo que significará sellar la paz entre nuestro país, Perú y Bolivia, mediante la realización de este proyecto que nos beneficiará a todos. Poco después, el Cónsul de Bolivia en Iquique, Dr. Germán Aliaga, fundador del Rotary Club de esta ciudad, en palabras emocionadas agradeció al señor Ramírez Bárcena, su aporte al proyecto con el trabajo leído en la sesión (El Tarapacá, 1 de octubre de 1950, citado en Ovando, 2016, p. 153-154).

De esta manera, y como señala Cornago (2016), la diplomacia no es una práctica sólo entre Estados sino una forma de relación social. Una ampliación del concepto que pretende retomar la diplomacia desde sus orígenes históricos y que permite describir muy bien lo que fueron los proyectos transfronterizos de la sociedad tarapaqueña.

Por otra parte, la diplomacia en sus términos actuales, estadocéntrica, se encuentra vacía de su sentido original que consistía en la voluntad de grupos humanos de relacionarse con tal de escapar de la guerra y la desconfianza, superando la alteridad como barrera de manera pacífica (Cornago, 2015; 2016).

En 1955 se dará un nuevo hito en las relaciones diplomáticas de ambos países, Víctor Paz y Carlos Ibáñez firman un tratado de complementación económica donde se intercambia petróleo boliviano por acero chileno en el puerto de Arica (González, 2012, p. 26-27).

Tarapacá ya había quedado marginada anteriormente con las conexiones ferroviarias que durante el apogeo del salitre se gestaron. Este nuevo periodo de encuentro entre ambos países le abría las puertas al sueño integracionista entre ambas regiones hermanas.

Lo que antes había sido el ferrocarril ahora sería la intensión de un camino internacional. El ánimo impulsado por la población iquiqueña y orureña, influenció en las decisiones del Gobierno de Bolivia bajo la presidencia de Hernán Siles; "en respuesta a ello los ministros de Obras Públicas de ambos países se reunieron en Iquique el 12 de marzo (de 
1958) y acordaron la construcción del camino internacional” (Ovando, 2016, p. 157).

Por otra parte, el proyecto no se visualizaba bajo la recurrente figura del efecto túnel, en el cual se dejarían aisladas a pueblos y caseríos que circundarán la carretera; al contrario, se pretendía generar una especie de "red de tipo dendrítico que integrara a toda la región transfronteriza" (González, 2012, p. 35). Las caravanas de la amistad se desarrollaron en primera instancia desde Oruro hacia Iquique, llegando los orureños un 21 de mayo al puerto de Tarapacá, fecha significativa al igual que la llegada de los Iquiqueños a Oruro, un día antes del 6 de agosto, día nacional de Bolivia.

Pese al esfuerzo realizado el año 1958 en el cual se desarrollarían las icónicas caravanas de la amistad entre Iquique Oruro, el proyecto de la carretera internacional que integrara a ambos lados se derribó, tal cual ocurrió durante la época del salitre con los proyectos ferroviarios. Junto a ello, y ya finalizando los años 50, se retomaría una nueva etapa conflictiva entre los Estados de Bolivia y Chile, motivadas por el conflicto de las aguas del río Lauca el año 1962.

Por último, cerraremos este acápite con el siguiente fragmento emitido por los iquiqueños el año 1960, donde se plasma el sentir de un pueblo:

Es preciso seguir golpeando la conciencia no solo de nuestros gobernantes y parlamentarios, sino que también la de nuestros propios dirigentes locales para evitar que en definitiva quede diferida una obra que durante muchos años ocupó la atención preferente de los ciudadanos y que llegó a cristalizarse en una realidad internacional en su etapa inicial y que por parte de Chile quedó inconcluso comenzada en sus estudios y construcción, ya que el camino de Iquique a Oruro logró imponerse después de largos años de perseverante labor. (El Tarapacá de Iquique, viernes 2 de septiembre de 1960, en González. 2012, p. 75)

Este conflicto de territorialidades de actores (para)diplomáticos se explica muy bien en la siguiente reflexión teórica que realiza Núñez, Sánchez y Arenas al referirse que, "la frontera se asocia a una espacialidad porosa, donde lo que se valora es la incorporación de la acción al mundo global o, exactamente, el capital globalizado; más del otro lado ella se ve reforzada, apuntalando como nacional y, por lo mismo cerrada en el contexto de conflictos limítrofes” (2013, p. 35). Si bien aquella reflexión hace referencia a la bipolaridad de la frontera contextualizada en la globalización actual, no cabe duda que también gráfica lo que acontecía durante el periodo de crisis del salitre y mediados del siglo XX.

Estos autores agregan que la espacialidad andina-fronteriza no fue ajena a las prácticas discursivas de los Estados, terminando por convivir con cosmovisiones locales, generando nuevas fronteras culturales (Núñez, Sánchez y Arenas, 2013). Referirse a los pueblos aymaras resulta ser aún 
más complejo que la dicotomía presentada en la disputa de la población tarapaqueña y la diplomacia estatal; y por ello configuran una tercera territorialidad.

\section{La tercera territorialidad: Entre comunidad y disputa interétnica}

Durante el ciclo de expansión del salitre la administración del Estado de Chile no había sido homogénea, viéndose con dificultad la implementación del aparato fiscal en las tierras altas de Tarapacá (Castro, 2014). Además, se sumaron dos inconvenientes. Primero, la poca población de chilenos que residían en las localidades andinas y segundo, el desinterés de chilenos (que vivían en la pampa y en la costa) en ocupar cargos públicos en aquellos pueblos (Castro 2013, p. 368). Por ambas razones, parte considerable de los funcionarios de subdelegaciones andinas eran indígenas y/o peruanos o bolivianos residentes de pueblos vallesteros, serranos y altiplánicos, sumado al bajo dote policial en esas zonas (2013, p. 370).

La utilización del instrumento fiscal por parte de los aymaras del altiplano chileno-boliviano para enfrentar los conflictos entre comunidades-localidades deCariquimas e Islugas en el lado chileno y Llicas en el lado boliviano por el uso de tierras agropastoriles (Castro, 2016), nos muestra una visión contraria al esencialismo cultural estático y pueril, pues las dicotomías entre lo nacional y étnico se agotan al observar las dinámicas de quienes habitan la frontera.

Lo que corresponde hablar de disputas interétnicas, en vez de hablar de disputas intraétnicas, al tratarse de indígenas bolivianos e indígenas chilenos cumpliendo el rol de funcionarios de los respectivos Estados, y haciendo uso de los instrumentos fiscales por los recursos productivos de altura en el espacio fronterizo (Castro, 2016).

La arremetida de los llicas en tierras de los cariquimas e islugas en busca suelo fértil, datan de la administración peruana de la provincia de Tarapacá. Periodo en el cual se inauguraba la variable de la soberanía de los estados-nacionales y donde los islugas, amparados por el nuevo límite jurisdiccional, invocaron la condición de pertenecer a territorio peruano con tal de salvaguardar sus tierras de pastoreo. Misma herramienta que utilizarán bajo la administración chilena, como señala la siguiente cita:

Ha habido años poco lluviosos y por consiguiente ha escaseado el pasto natural cordillerano, lo que ha motivado grandes mortalidades de animales. Es de suponer el grave daño que tienen que soportar estos pobres (indígenas) en tiempo de sequedad y todavía más, contemplar con vista apacible, que nuestros campos sean asolados por ganaderos y recuas que de ex profeso se internan de la república de Bolivia a pastar a nuestro territorio (ITAR-33, Dirección de Obras 
Públicas 1916, informe del Ingeniero de la Provincia sobre internación ilegal y masiva de ganaderos bolivianos por la frontera, Iquique 1/2/1920, s.f., citado en Castro, 2016, p. 134).

Los conflictos entre los Llicas, Islugas y Cariquimas por las tierras de pastoreo dan muestra de una modificación de las lógicas étnicas que integraron la variable de frontera de los Estados, haciendo aún más complejo el imaginario fronterizo de los habitantes de las comunidades. Un derrotero histórico entre los siglos XII y XIX con la entrega de títulos de propiedades indígenas de los pueblos, pasando por las demarcaciones estatales; éstos últimos se traslaparían como una concepción territorial más, en la cual se intervendría el imaginario existente.

Una intervención de estos imaginarios y apropiación de los espacios fue el uso de las apachetas, las que simbolizan el cruce y el encuentro del viajante para el pueblo aymara, pero que la consolidación de los Estados las modificó, tomando algunas apachetas para transformarlas en demarcadores de soberanía.

La integración de dispositivos de la cultura hegemónica -las naciones de Bolivia y Chile- en las comunidades aymaras de Cariquima e Isluga fueron herramientas para la resolución de conflictos con comunidades vecinas del lado boliviano. Por lo demás, este problema tiene como principal causa las nuevas demarcaciones de fronteras estatales, que demarcaba las tierras agro-pastoriles de un lado, y de otro de las nuevas fronteras-límites político-administrativas. Donde, "los cargos públicos sirvieron como un mecanismo para resolver diferencias, rivalidades y conflictos que operaban en muchas de las localidades andinas desde el periodo peruano, e incluso antes" (Castro, 2013, p. 376)

Aquello produjo que la fragmentación de las propiedades colectivas se diera paso a resoluciones de conflictos desde "lógicas de la propiedad privada y/o sucesorial” (Castro, 2016, p. 114) para integrarse al lenguaje de los Estados, y que fueron teniendo una escalada diplomática.

La fragmentación de las comunidades-localidades indígenas, de la cual habla Castro, se expresa en lo acontecido en el pueblo fronterizo de Huatacondo a comienzos del 1930, en una petición de los vecinos de aquella comunidad para cambiar al inspector de Distrito por considerar una "vergüenza (el) tener a un boliviano como autoridad habiendo otras personas, sobre todo, otros chilenos más aptos para el cargo" (ITAR, vol. 2, Gobernación de Pisagua 1933, Huatacondo 22/1/1933, s.f., citado en Castro, 2016, p. 137).

En los años venideros se dispondrá por parte del Estado la instalación de dispositivos disciplinarios en el espacio andino para chilenizar a la población indígena, cuestión que se liga a la razón de Estado que menciona Esteves (2003) y Haesbaert (2013). 


\section{Conclusiones}

Al inicio de la crisis estructural, la región de Tarapacá se encontraba enceguecida por lo que fue el auge del salitre. Empresarios y trabajadores, así como las autoridades, estaban más preocupadas en atender otros temas, siempre entorno a la sociedad que la producción del salitre había levantado, y donde las propuestas de nuevas políticas alternativas eran marginales (Donoso, 2011).

Sin embargo, Ovando y González advertían que durante el siglo XX, "los diversos actores diplomáticos chileno-bolivianos responderían a la particularidad territorial de Tarapacá y Oruro, de cómo se han apropiado de dicho territorio distintas subjetividades provenientes de diferentes escalas de acción, donde la transfronteriza tendría una importancia estratégica" (2014, p. 45). Cuestión que, si bien ya había sido promovida en materia económica por proyectos de la élite minera, se profundizará durante el periodo de crisis estructural del salitre como una estrategia política regional mientras las relaciones entre los Estados se debatían entre demandas y litigios.

El encuentro y distanciamiento de la diplomacia hegemónica de los Estados centrales se confrontaba con las tentativas de los actores locales de las provincias de ambos países. Conflicto diplomático/paradiplomático que era también un enfrentamiento entre los imaginarios geográficos (Baily, 1989) y territorialidades disociadas (Benedetti, 2014).

Sin embargo, en el caso de Tarapacá no se reduce a dos pares opuestos, sino que a tres territorialidades. Siendo las comunidades-localidades indígenas, el lugar más próximo de la frontera, donde el entramado de territorialidades se hace más complejo (Castro, 2016), cohabitando con las dos anteriores y sumando significaciones culturales históricas. Si bien las fronteras reflejan la existencia de diferencias entre grupos (Newman, 2006), no se reduce a la idea de separación (Agnew, 2006).

Jessop (2004) nos menciona que parte del éxito de las regiones transfronterizas depende de las formas discursivas que elaboran para convencer y obtener el apoyo para los proyectos de integración, sumando condiciones extradiscursivas, tales como la materialidad institucional de interdependencia.

Como se había mencionado anteriormente, la espacialidad fronteriza no se agota en esta noción de límite que establece el dispositivo de soberanía estatal o lo que Agnew (2005, p. 60) denomina como trampa territorial donde el Estado se constituye como único referente geográfico. No es sólo el territorio estatal sino que es un espacio de discontinuidades y de múltiples-territorialidades (Haesbaert, 2013) correspondiente a representaciones de producción cultural, social e histórica en el ámbito del poder y la configuración del espacio que se oponen, yuxtaponen y ensamblan. 
Se oponen los imaginarios espaciales y las territorialidades de los distintos actores diplomáticos mediante los comités pro-camino, pro-ferrocarril, los discursos de autoridades locales y, aún más significativas, las caravanas de la amistad de 1958. El hermanamiento de las ciudades de Iquique y Oruro son ejemplos de actores subnacionales ejerciendo un papel diplomático y, como señala Navia y Córdova (2018) "respecto a la paradiplomacia y el desarrollo de otras regiones transfronterizas, se trata de perspectivas locales que logran sincronía y complicidad entre los actores" (p. 17), pero donde pareciera que siempre es necesario el apoyo de los Estados.

En esta oposición es que se yuxtapone la visión del Estado por sobre la diplomacia como heterología de los actores regionales, que marcaría la memoria e identidad de ambos pueblos (González, 2012, p. 34) y es que, "la frustración generada por el fracaso recurrente de esos proyectos se transformó en un acicate hasta volverlo en un verdadero proyecto político de desarrollo regional” (Ovando y González, 2014, p. 37); proyecto que perdura en la memoria local y en la configuración de un territorio transfronterizo.

Con la crisis y los conflictos diplomáticos comienza a discutirse la necesidad de vigilancia en la frontera chileno-boliviana, sobre todo un espacio fronterizo, en la circulación de mercancías como también de personas. Como menciona un documento emitido desde el gobierno hacia la Intendencia de Tarapacá sobre,

la necesidad de reforzar el servicio de resguardo de los distintos puntos de la Provincia de Tarapacá, fronterizos con Bolivia, que son objeto de frecuentes y perjudiciales incursiones de autoridades y particulares bolivianos (...) considérese el Escuadrón de "Pisagua" propuesto por usted. (ITAR-1203, Archivos Confidenciales, fecha 12/01/1923, citado en González y Leiva, 2016, p. 25).

Pero también es un espacio en el cual se ensamblan territorialidades como en el caso de las comunidades-localidades mencionadas por Castro (2008; 2016), donde se incorpora instrumentos fiscales para resolver problemáticas locales entre comunidades del otro lado de la frontera. Se trata de una territorialidad que no deja de lado la dinámica transfronteriza; enriqueciendo aún más el espacio fronterizo de Tarapacá.

Como señala Tapia Ladino (2017, p. 75) "lo transfronterizo se constituye desde abajo”, y es que desde la dinámica de quienes habitan el espacio fronterizo desplegando distintas prácticas sociales fronterizas se configura lo trans. Éstas hacen que no se reduzca en la concepción territorial del Estado, sino que se observen dinámicas que van más allá de aquel límite fronterizo, que se proyecta una territorialidad transfronteriza o múltiple. Territorialidades en las que los actores subnacionales configuran el espacio fronterizo. 


\section{Agradecimientos}

Tesis Magíster en Relaciones Internacionales y Estudios Transfronterizos, del Instituto de Estudios Internacionales, Universidad Arturo Prat. Tesis financiada por el Proyecto FONDECYT 1160209. 


\section{Bibliografía}

Agamben, G. (2011). ¿¿ué es un dispositivo?, Sociológica, 26 (73), 249-264.

Amilhat-Szary, A. L. (2013). Cultura de fronteras. En B. E., Nates. (ed.). Frontera, fronteras,(pp. 43-60). Manizales, Colombia: Universidad de Caldas.

Amilhat-Szary, A. L. (2016). Gentes y agentes, condiciones paradiplomáticas de la creación de una frontera móvil. En S. González, N. Cornago, y C., Ovando. (eds). Relaciones transfronterizas y paradiplomacia en América Latina. Aspectos teóricos y estudio de casos.(pp. 47-72).Santiago, Chile:Editorial RIL.

Agnew, J. (2005). Geopolítica. Una re-visión de la política mundial.Madrid, España: Trama Editorial.

Agnew, J. (2006). Entre la geografía y las relaciones internacionales.Tabula Rasa, (5), 85-98.

Ashley, R. (2009). Desenredar el Estado soberano. Una doble lectura de la problemática de la anarquía. En Arturo Cruz (ed). El constructivismo y las relaciones internacionales. México, D.F, México: Editorial Centro de Investigación y Docencia Económica.

Baily, A. (1989). Lo imaginario espacial y la geografía. En defensa de la geografía de las representaciones. Anales de Geografía de la Universidad Complutense, (9), 11-19.

Balibar, É. (2005). Fronteras del mundo, fronteras de la política. Alteridades, 15 (30), 87-96.

Balibar, E. (2009). Europe as borderland. Environment and planning D: Society and space, 27(2), 190-215.

Benedetti, A. (2014). Espacios fronterizos del sur sudamericano. Propuestas de un modelo conceptual para su estudio. Estudios Fronterizos. Revista de Ciencias Sociales y Humanidades. Nueva época, 15 (29), 11-47.

Benedetti, A. y Salizzi, E. (2011). Llegar, pasar, regresar a la frontera. Aproximación al sistema de movilidad argentino-boliviano. Revista Transporte y Territorio, (4), 48-179.

Brambilla, C. (2015). Exploringthecriticalpotential of theborderscapes concept. Geopolitics, 20(1), 14-34. 
Castro, L. (2008). El Estado chileno, los agentes fiscales y el temprano ordenamiento administrativo del espacio andino de la provincia de Tarapacá (1880-1930). Chungará (Arica), 40(2), 219-233.

Castro, L. (2013). El espacio andino y la administración estatal durante el ciclo salitrero. Tarapacá, 1882-1933. En S. González. (comp.) La sociedad del salitre. Protagonistas, migraciones, cultura urbana y espacios públicos, (pp. 361-391). Santiago, Chile: RIL Editores.

Castro, L. (2014). Tráfico mercantil andino, comerciantes indígenas y fiscalización estatal (Tarapacá, norte de Chile 1880-1938). Revista de Indias, 74(261), 561-590.

Castro, L. (2016). Cariquimas, Islugas y Llicas: la frontera chileno-boliviana de Tarapacá y las disputas interétnicas por los recursos productivos de altura (1883-1931).En S. González, C. Ovando e I. Breton. (eds.)Del hito a la apacheta. Bolivia-Chile: otra lectura de cien años de historia transfronteriza (1904-2004),(pp. 113-144). Santiago, Chile: RIL Editores y Universidad Arturo Prat.

Cornago, N. (2016). Diplomacia como heterología: pluralismo social y múltiples mediaciones institucionales en la frontera. En S. González, C. Ovando e I. Breton. (eds.)Del hito a la apacheta. Bolivia-Chile: otra lectura de cien años de historia transfronteriza (1904-2004),(pp. 17-46). Santiago, Chile: RIL Editores y Universidad Arturo Prat.

Cornago, N. (2015). (Para) Diplomatic Cultures: Old and New. En J. Ditner y F. McConnell (eds.), Diplomatic Cultures and International Politics: Translations, Space and ASlternatives. Nueva York, UnitedStates: Routledge.

Cornago, N. (2009). La diplomacia como heterología.Pais Vasco, España: Universidad del País Vasco, Leioa (manuscrito).

Constantinou, C. M. (2010). Diplomacy, Spirituality, Alterity. En C.M. Constantinou y J. Der Derian (eds.), Sustentable Diplomacies (pp. 67-89). Londres, UK: Palgrave.

Couyoumdjian, J. R. (1974). El mercado del salitre durante la primera guerra mundial y la postguerra: 1914-1921: notas para su estudio.

Der Derian, J. (1998). Todas las cosas post: teoría y tradición en las relaciones internacionales tardías. En C. Nasi (comp). Postmodernismo y relaciones internacionales. (pp. 25-51). Bogotá, Colombia: Ediciones Unidades.

Donoso, C. (2011). Debates y reflexiones en torno a la crisis económica en Tarapacá (1934-1953): notas preliminares. Revista de Historia Social y de las Mentalidades, 13(2). 
Esteves, P. (2006). Pour une généalogie de l'etatSouverian territorial. Revista de Sociología e Política, (27), 15-32.

Foucault, M. (1979). El ojo del poder. En J.Betham. El Panóptico.(pp.926). Madrid, España:Ediciones de la Piqueta.

Foucault, M. (2006). Seguridad, Territorio, Población. Cursos en el Collège de France (1977-1978). Paris, Francia: Fondo Cultura Económica. México.

González, S. (2006). Cruzando los Mallkus. Las migraciones bolivianas pendulares durante las grandes crisis salitreras (1914 - 1933). Revista de Historia Social y de las Mentalidades, 10(2), 155-192.

González, S. (2008). La llave y el candado. El conflicto entre Perú y Chile por Tacna y Arica (1883-1929), Santiago, Chile: Ediciones Lom.

González, S. (2009a). El Norte Grande de Chile: la definición histórica de sus límites, zonas y líneas de fronteras y la importancia de las ciudades como geosímbolos fronterizos. Revista de Historia Social y de las Mentalidades, 7 (13), 9-42.

González, S. (2009b). La presencia boliviana en la sociedad del salitre y la nueva definición de la frontera: auge y caída de una dinámica transfronteriza (Tarapacá 1880-1930).Chungará (Arica), 41(1), 7181.

González, S. (2011). Las históricas relaciones entre Tarapacá y Oruro: la frustrada tentativa de integración transfronteriza durante ciclo de expansión del salitre (1864-1928). Revista de geografía Norte Grande, (50), 63-85.

González, S. (2012). Sísifo en los Andes. La (frustrada) integración física entre Tarapacá y Oruro: las caravanas de la amistad de 1958. Santiago, Chile: RIL.

González, S.; Calderón, R. y Pablo Artaza. (2016). El fin del ciclo de expansión del salitre en Chile: la inflexión de 1919 como crisis estructural. Revista de Historia Industrial. 25 (65), 83-110.

González, S. y Leiva, S. (2016). El Norte Grande durante el ciclo del salitre: la política salitrera y la política exterior en la formación de un espacio transfornterizo (Bolivia y Chile 1880-1929). Estudios atacameños, (52), 11-29.

Haesbaert, R. (2013). Del mito de la desterritorialización a la multiterritorialidad. Culturas y representaciones sociales, 8 (15), $9-42$. 
Jessop, B. (2004). La economía política de la escala y la construcción de las regiones transfronterizas. EURE (Santiago), 30(89), 25-41.

Medina García, E. (2006). Aportaciones para una epistemología de los estudios sobre fronteras internacionales. Estudios fronterizos, 7(13), 9-27.

Nasi, C. (1993). La Encrucijada Teórica Actual: Algunas reflexiones en torno al caso de la disciplina de las Relaciones Internacionales. Colombia Internacional, 21, 22-32.

Nava, K. M., y Córdova, G. (2018). Paradiplomacia y desarrollo económico en la región transfronteriza de Reynosa-McAllen. Estudios fronterizos, 19.

Newman, D. (2006). Thelinesthatcontinue to separateus: borders in ourborderless' world. Progress in Human geography, 30(2), 143-161.

Núñez, A., Sánchez, R., y Arenas, F. (2013). Fronteras en movimiento e imaginarios geográficos. La cordillera de Los Andes como espacialidad sociocultural. Santiago, Chile: Geolibros-RIL Editores.

Núñez, A. (2013). Geografía, historicidad y hermenéutica: Conversaciones sobre geografía con el geógrafo francés Dr. Alain Musset. Revista de geografía Norte Grande, (54), 257-268.

Ovando, C. y Ramos, R. (2016). Imaginarios geográficos en torno a la franja fronteriza de Tarapacá: el estado y los habitantes/migrantes. Scripta Nova. Revista Electrónica de Geografía y Ciencias Sociales. [En línea].20 (529)

Ovando, C., y González, S. (2014). La relación bilateral chileno-boliviana a partir de las demandas tarapaqueñas: aproximación teórica desde la paradiplomacia como heterología. Estudios internacionales (Santiago), 46(177), 35-64.

Ovando, C. y González, S. (2016). Algunas expresiones de pluralismo diplomático chileno hacia Bolivia y Perú vistos desde el Norte Grande. En S.González Miranda, N. Cornago, y C. Ovando. (eds). Relaciones transfronterizas y paradiplomacia en América Latina. Aspectos teóricos y estudio de casos. Santiago, Chile: Editorial RIL.

Rodrigues, T. (2013). Agonismo y genealogía: hacia una analítica de las Relaciones Internacionales | Agonism and Genealogy: towardsananalytics of internationalrelations. Relaciones Internacionales, 0(24). 
Spíndola, O. (2016). Espacio, territorio y territorialidad: una aproximación teórica a la frontera. Revista mexicana de ciencias políticas y sociales, 61(228), 27-56.

Tapia, M. (2017). Las fronteras, la movilidad y lo transfronterizo: Reflexiones para un debate. Estudios fronterizos, 18(37), 61-80.

Tapia, M. y Ovando, C. (2013). Los Andes Tarapaqueños, nuevas espacialidades y movilidad fronteriza: ¿barrera geográfica o espacio para la integración? En A. Núñez, R. Sánchez y F. Arena (eds.). Fronteras en movimiento e imaginarios geográficos.La cordillera de los Andes como espacialidad sociocultural.(pp. 243-274) Santiago, Chile: RIL editores. 